Original Research Paper

\title{
Investigate the Extrinsic and Intrinsic Motivational Factors of Knowledge Transfer in the Hospitals
}

\author{
${ }^{1}$ Ahmad Aabed Al-Hayy Al-Dalaien, ${ }^{1}$ Sulfeeza Mohd Drus, \\ ${ }^{1}$ Hairoladenan Kasim and ${ }^{2}$ Ali Taha Al-Oqaily \\ ${ }^{1}$ Department of Information Systems, University Tenaga Nasional, Malaysia \\ ${ }^{2}$ Department of Software Engineering, Ajloun National University, Jordan
}

\section{Article history}

Received: 16-08-2019

Revised: 08-11-2019

Accepted: 15-01-2020

Corresponding Author:

Ahmad Aabed Al-Hayy Al-

Dalaien

Department of Information

Systems, University Tenaga

Nasional, Malaysia

Email: ahmad.abed200826@yahoo.com

\begin{abstract}
The value of services in knowledge-intensive organizations like the hospitals is created by the tacit knowledge of the health staff. The weak knowledge transfer activities among the health staff effects on the performance level of the health care services. Hospitals are dependent on continuously learning from mistakes and to make improvements and then to transfer this newly acquired knowledge between units and workers in the organization. It is important to enhance the knowledge transfer behaviors of knowledge source and recipients in the hospitals. This study aims to investigate the extrinsic and intrinsic motivational factors that would be adopted to improve the knowledge transfer processes among the health staff. The data of this study were collected from 475 doctor and nurses that work in three Jordanian hospitals; Albashir Hospital, Jordan University Hospital and Al-Issra Hospital. The collected data were analyzed using many tests such as validity, reliability, demographic and descriptive analysis. The significant results show that there are many extrinsic motivational factors would be adopted to improve the knowledge transfer by the knowledge source and recipients such as reward, ideal salaries, promotions, satisfaction of work position, stability of labor and reputation feedback. On the other hand, there are many intrinsic motivational factors that would be applied to enhance the knowledge transfer such as arduous relationship, altruism, shared understanding, champions and enjoyment to help others. This study helps the hospitals to identify the motivational factors that would be adopted to improve the knowledge transfer processes in order to enhance the quality of health care services.
\end{abstract}

Keywords: Hospitals, Knowledge Transfer, Motivational Factors, Extrinsic, Intrinsic

\section{Introduction}

Nowadays, the globalization of businesses increases the competition between the organizations of same industry. The organizations focus on enhancing the competitive advantage of their product and services (Serrat, 2017). However, the enhancement of competitive advantage is not simple due to dynamic changes of businesses environments (Serrat, 2017). business success is dependent on the provision of the products and services accurately at the right time. Thus, the employees need to perform their tasks in the best ways that they can by using the knowledge that are stored in their minds (Cuervo-Cazurra et al., 2018; Cui and $\mathrm{Wu}, 2016)$. This type of knowledge can be referred to as tacit knowledge; which requires learning and applying the new and innovated knowledge in the working environment (Alaarj et al., 2016)

Health institutions like hospitals are seen as "knowledge-intensive" organizations (Grossi et al., 2019; Goodall and Baker, 2015; Tsai, 2014; Kim et al., 2012), where the value of services in the hospitals is created by utilizing the skills, knowledge and experience of the health staff. Thus, it is important to continually develop the knowledge of health staff to improve the provision of services by the hospitals. The knowledge development in hospitals could enhance the innovations and teamwork in the context of the provided services such as surgeries, new medicines discoveries and avoidance 
of repetition of past treatment mistakes (Yacoub et al., 2014; Kim et al., 2012).

In knowledge-intensive organizations like hospitals, knowledge transfer between the health staff is one of the most important knowledge management implementations to improve the employees' tacit knowledge (Prestmo et al., 2015; Feet and Næss, 2015; Alhalhouli et al., 2014). Knowledge transfer is the process of sending knowledge from the knowledge source to the knowledge recipients and acceptance of the transferred knowledge by the recipients (Jasimuddin et al., 2017; Paulin and Suneson, 2015; Sheng et al., 2013).

Several studies mentioned that one of the most important aspects of knowledge transfer in the hospitals is the behaviors of employees toward knowledge transfer (Grossi et al., 2019; Goodall and Baker, 2015; Tsai and Cheng, 2012; Wu and Zhu, 2012; Sheng et al., 2013; Tsai, 2014; Radaelli et al., 2014; Feet and Naess, 2015; Svärd, 2017). These studies define knowledge transfer behavior as the employees' norms or attitudes in sharing, accepting and applying knowledge in the working environment. Without positive behaviors towards knowledge transfer among the health staff in hospitals, the opportunity to develop and enhance the health staff's knowledge may not be successful.

Nevertheless, there are many challenges in the knowledge transfer process among the health care employees in hospitals. The following represent the main challenges faced by hospitals in the knowledge transfer behaviours of knowledge sources and knowledge recipients:

a. Challenges related to knowledge source:

- Ego personality, which means that the employee thinks that his/her knowledge is private or personal success key and it should not be known by others (Feet and Næss, 2015)

- The employees are reluctant to share their knowledge because there are no personal rewards or returned benefits (Wilkesmann et al., 2007; Feet and Næss, 2015)

b. Challenges related to knowledge recipients: There are many reasons that discourage the health staff in hospitals to accept and apply the transferred knowledge from other employees such as;

- The employees do not trust and value the knowledge shared by the knowledge sources and feel that their current knowledge is more valuable than the new shared knowledge (Feet and Næss, 2015; Alaaraj et al., 2018)

- Knowledge overloaded whereby employees have to spend tremendous amount of time and efforts to retrieve the required valuable knowledge (Feet and Næss, 2015; Alaarj et al., 2016)

- No past knowledge sharing assessment to know how the employees develop their tacit knowledge using the recently acquired shared knowledge (Feet and Næss, 2015)

Hence, the main objective of this study is to investigate the motivational factors that could enhance the knowledge transfer among healthcare employees in hospitals. The next section presents the theoretical considerations of this study, the third section clarifies the research methodology, the fourth section discuss the study results and the last section provides the study conclusion and future works.

\section{Theoretical Considerations}

There are several terms used in the literature to describe knowledge transfer such as knowledge flow, knowledge sharing and knowledge acquisition. For terminological reasons, it has been decided to combine these definitions under the term knowledge transfer as it is more established in various literary sources. Figure 1 provides a schematic representation of knowledge transfer. Simply put, Knowledge transfer is the process of tacit and explicit knowledge interchange between individuals, groups, or business entities whereby collectively new information will be created (Wang and Hou, 2015; Argote and Ingram, 2016).

Nonaka and Takeuchi (2015) indicated that there are many approaches to knowledge transfer. For the focus of this research, two of the approaches that are applicable include (1) externalization approach where tacit knowledge is transferred as explicit form such as speaking or writing the tacit knowledge of knowledge source and this knowledge is documented and (2) internalization approach where the shared explicit knowledge (such as documents and oral stories) is embodying into tacit knowledge of recipients.

\section{Knowledge Transfer in Hospitals}

Hospitals can be characterized as "knowledge-intensive" organizations (Grossi et al., 2019; Dammaj et al., 2016). This means that most of the value in the hospitals is created by utilizing the skills, knowledge and experience of the employees (Goodall and Baker, 2015). In a hospital setting, this is manifested as the value creation takes place in the interaction by health care professionals and patients (Feet and Næss, 2015). Knowledge-intensive organizations, such as hospitals, are dependent on continuously learning from mistakes and to make improvements and then to transfer this newly acquired knowledge between units and workers in the organization (Dammaj et al., 2016; Bustinza et al., 2019; Kim et al., 2012).

In this study, the most important knowledge transfer approaches are the socialization, whereby the process of sharing tacit knowledge, including skills and ideas, 
through face-to-face communication, dialogue or shared experiences, often through joint activities, observation, imitation and practice rather than written or verbal instructions. Socialization may also occur during an informal gathering outside of the workplace. The socialization approach is important in this research to motivate the knowledge transfer among the employees in the working environment. However, the organizations that have knowledge transfer systems could apply other knowledge transfer approaches such as externalization and internalization.

In externalization approach, the process by which an individual attempt to represent his or her tacit knowledge and makes it accessible to others. It refers to converting and articulating tacit knowledge to new explicit knowledge. The successful conversion of tacit knowledge into explicit knowledge depends on the sequential use of metaphor, analogy and model. based on externalization approach, the internalization could be conducted through the creation of new tacit knowledge from explicit knowledge (e.g., the learning-by-doing, onthe-job-training and understanding that results from reading or discussion). Figure 2 illustrates the various approaches of knowledge transfer.
The knowledge transfers between health staff in hospitals are very important to develop the knowledge of health staff in order to enhance the health care services that provided in hospitals (Alhalhouli et al., 2014; Feet and Næss, 2015; Prestmo et al., 2015; Wang and Hou, 2015; Baporikar, 2017; Suliman et al., 2018). Enhancing the quality of treatment in hospitals leads to achieve the patients' satisfaction and increase the hospitals competitive advantage over other hospitals (Prestmo et al., 2015; Suliman et al., 2018).

On the other hand, Hislop et al. (2018), Suliman et al. (2018) and Prestmo et al. (2015) argued that the knowledge transferring between health staffs impose best-practices for innovating new medical treatment and medicines. The treatments and medicines should be developed and enhanced continually to solve the new health challenges and diseases. For example, St. Olav University hospital in Norway supports the collaboration between health specialists to find better solutions for the new challenges in health domains (Suliman et al., 2018; Prestmo et al., 2015). This collaboration involves about 9000 surgeries in Norway every year and the cost saving estimation based on this collaboration is about 130 million Norwegian Krone/per year.

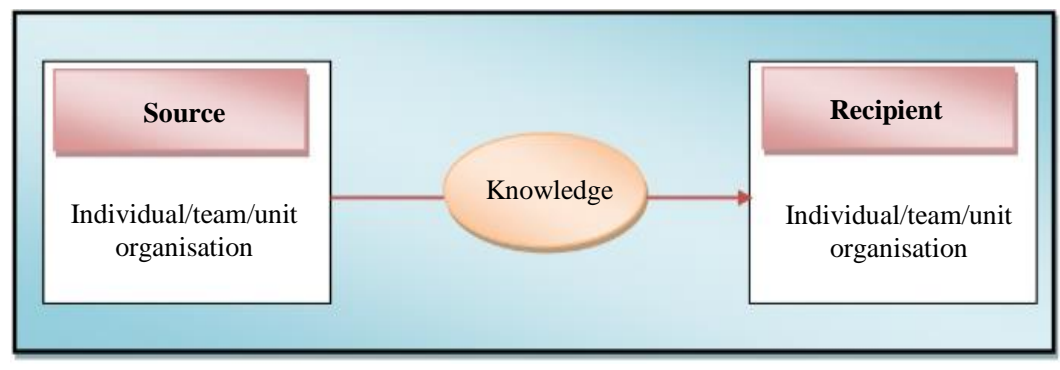

Fig. 1: Schematic representation of knowledge transfer (Kumar and Ganesh, 2009)

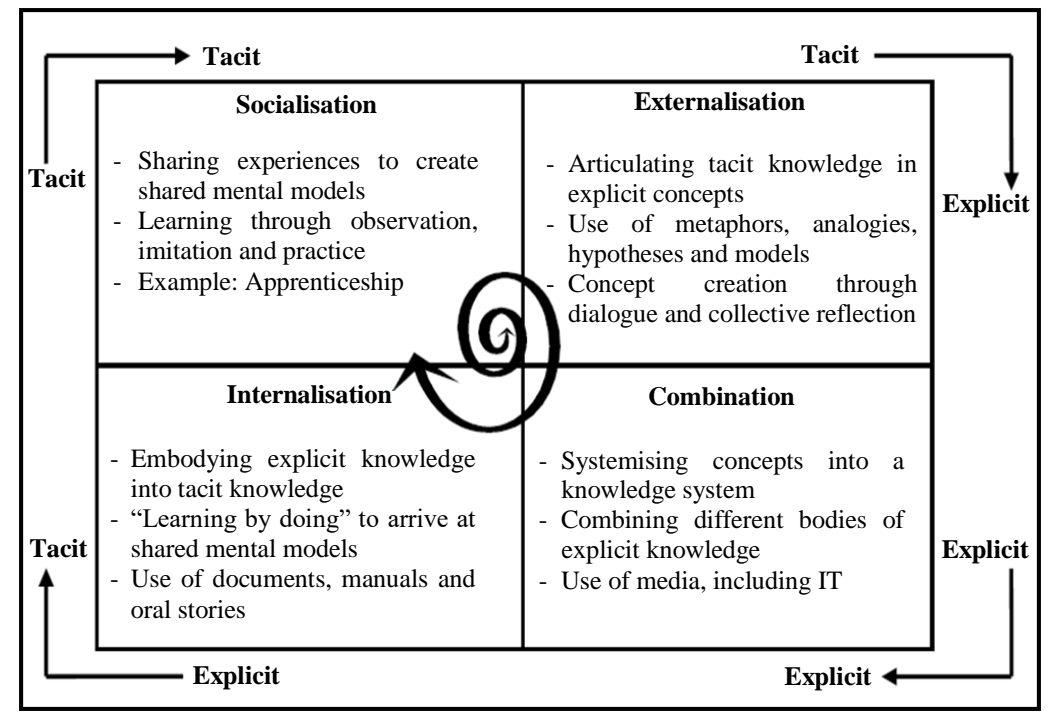

Fig. 2: Knowledge transfer approaches (Nonaka and Takeuchi, 2015) 
Therefore, the knowledge transferring between health staff in hospitals is necessary in order to improve the competitive advantages of hospitals such as improve the health care services, reduce the treatments costs and innovate new health solutions. However, the knowledge transferring process in hospitals may fail due to the workers' behaviors in transferring knowledge (Alhalhouli et al., 2014; Feet and Næss, 2015; Prestmo et al., 2015; Wang and Hou, 2015; Baporikar, 2017; Suliman et al., 2018; Drus et al., 2017). Understanding the motivations for knowledge transfer among health staff is an important success factor of knowledge transfer in hospitals.

The successes of knowledge transfer processes in the hospitals are determined by many properties of knowledge transfer elements, which are (Szulanski, 1996; Tsai and Cheng, 2012; Feet and Næss, 2015):

(i) Properties of the source of knowledge: The source of shared knowledge (workers who share knowledge) should be motivated to share knowledge and perceived as reliable of shared knowledge. The workers behaviour of knowledge sharing may be weak due to lack of motivation (such as no rewards for the shared knowledge), or ego personality (the workers see that their knowledge is private and no person have the right to know it)

(ii) Properties of the recipient of knowledge: The knowledge recipients should be motivated to accept and implement the shared knowledge from other workers. However, the recipients may not accept the shared knowledge due to many reasons such as lack of motivation (not profits from accept and implement the knowledge), large capacity of shared knowledge (there is a lot of workers share large capacity of knowledge, so what the better knowledge), un-trusted knowledge (the recipient does not trust the shared knowledge) and weak personal communication (not accept the knowledge to personal communication problems with sources)

Based on these properties of knowledge transfer elements, there are many challenges that could hinder the success of knowledge transfers in the hospitals such as ego personality, none returned benefits and weak trust between the knowledge sources and recipients. Thus, it is necessary to address these challenges to improve the knowledge transfer processes in the hospitals.

\section{Theories of Motivating Knowledge Transfer}

The weak behaviour and attitudes of knowledge sources and recipients toward the knowledge transfer could lead to the fail of knowledge transfer in the working environment, theories such as economic exchange and social exchange (Lombardi et al., 2019; Zhang et al., 2017; Diep et al., 2016).
The satisfaction of employees inside the organization is important to motivate the employee's behaviours of accomplish the working tasks effectively (Hanaysha and Majid, 2018; Raziq and Maulabakhsh, 2015). In economic exchange theory, it is believed that individuals will behave by rational self-interest (Alhalhouli et al., 2014; Lin, 2007), where knowledge transfers will occur when its rewards exceed its costs (Lin, 2007). Hence, expected rewards imply that, if employees believe that they will receive extrinsic or tangible benefits such as monetary rewards, promotion, or educational opportunity from their knowledge sharing, they would develop a more positive attitude towards knowledge transfer. The economic exchange theory suggests that the employees' behaviours could be motivated using extrinsic or tangible benefits of knowledge transfer activities. Figure 3 illustrates the economy exchange theory.

On the other hand, the social exchange theory considered that the intrinsic or intangible benefits could motivate the behaviours of knowledge transfer (Serenko and Bontis, 2016; Razmerita et al., 2016; Alhalhouli et al., 2014; Lin, 2007). Social exchange differs from economic exchange in that social exchange entails unspecified obligations. In contrast to economic commodities, the benefits involved in social exchange do not have an exact price in terms of a single quantitative medium of exchange and the nature of the return cannot be bargained about. This is why only social exchange tends to engender feelings of personal obligation, gratitude and trust. For example, the initial offer of knowledge to a newcomer in an organization entails a friendly relationship and the individual who has received the help feels an obligation to reciprocate. If the newcomers reciprocate properly, they will prove themselves trustworthy and exchange relations will be established (Serenko and Bontis, 2016; Razmerita et al., 2016; Ahmad et al., 2018; Kasim and Drus (2018).

Based on the above two theories, the behaviours of knowledge transfer can be motivated through four elements which are: (1) Effective extrinsic benefits for the employees; (2) Effective intrinsic benefits for the employees; (3) Extrinsic and intrinsic benefits are related to the performance of knowledge transfer activities that are conducted by the employees.

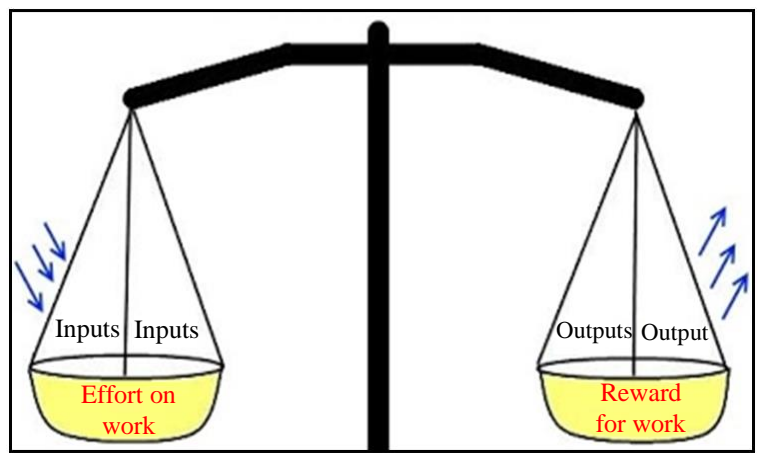

Fig. 3: Economy exchange theory (Adams, 1963) 


\section{Motivation Factors of Knowledge Transfer}

The sources and recipients of knowledge should be motivated to expand knowledge transfer efforts in order to enhance the growth of knowledge resources in the organization. The knowledge sources' behavior must be improved by motivating them to share valuable and qualified knowledge with other workers. On the other hand, the knowledge recipients' behavior must be improved by motivating them to accept and apply the shared knowledge in the working environment.

A number of researches have been conducted in determining the factors that motivate the individuals to transfer knowledge in organizational setting such as Ko et al. (2005; Martín Cruz et al., 2009; Hung et al., 2011; Yan and Davison, 2013; Caligiuri, 2014; Alhalhouli et al., 2014; Al-Dala'Ien et al., 2015; 2016; Feet and Næss, 2015; Wang and Hou, 2015; Baporikar, 2017; Alaarj et al., 2015; 2017a; 2017b; Alksasbeh et al., 2018; Al-Oqaily et al., 2015). Based on their researches, it can be observed that the motivational factors can be grouped as either extrinsic or intrinsic aspect. This is also notion by Osterloh and Frey (2000) that the motivation of workers' behaviors of knowledge transfer can be categorized as extrinsic and intrinsic motivations. The most important extrinsic factors (based on economic exchange theory) are as the following:

(i) Rewards: Ideal rewards based on the effectiveness of knowledge transfer could encourage the employee's behaviours (sources) to share knowledge (Hung et al., 2011; Yan and Davison, 2013; Caligiuri, 2014; Alhalhouli et al., 2014; Wang and Hou, 2015; Feet and Næss, 2015; Baporikar, 2017)

(ii) Promotions: Knowledge transfer activities in the organization would be enhanced through conduct the promotions in working environment based on the effectiveness of knowledge transfer behaviours (share knowledge by sources and apply the shared knowledge by recipients) (Yan and Davison, 2013; Alhalhouli et al., 2014)

(iii) Salaries: The knowledge transfers behaviours of knowledge sources and recipients can be encouraged through provide suitable salaries to satisfy the extrinsic needs of the employees (Wang and Hou, 2015)

(iv) Selection of workers positions: The knowledge transfers behaviours of knowledge sources and recipients can be encouraged through assigning the working positions based on the effectiveness of employees' knowledge transfer (Caligiuri, 2014)

On the other hand, the most important intrinsic factors are as the following:

(i) Altruism: The good relationship between the employees in working environment could encourage the sources to share knowledge and the recipients to apply the shared knowledge (Hung et al., 2011; Yan and Davison, 2013; Wang and Hou, 2015)

(ii) Trust: The knowledge recipients would be motivated to accept and apply the shared knowledge when the characteristics of knowledge sources are trusted i.e., experience years and qualification levels (Feet and Næss, 2015; Baporikar, 2017)

(iii) Training on positive behaviours of knowledge transferring: The sources and recipients' behaviours of knowledge transfer can be motivated through train them to enjoy the social communication with other people (Caligiuri, 2014)

(iv) Evaluate the quality of shared knowledge: The knowledge recipients would be motivated to accept and apply the shared knowledge when the quality of the shared knowledge is evaluated by experts in the organization (Baporikar, 2017)

(v) Awareness of knowledge sharing benefits: The awareness level of knowledge transfer importance in the organization (i.e., the perceived benefits) should be clarified for the employees (knowledge sources and recipients) to motivate their behaviours of knowledge transfer (Alhalhouli et al., 2014; Feet and Næss, 2015)

(vi) Champions: Conduct competitions in working environment to show the champions of knowledge transfer is effective factor to motivate the employee's behaviours of knowledge transfer (Feet and Næss, 2015). Table 1 lists all the motivational factors for knowledge transfer that discussed in the past studies

Table 1: Motivational factors of knowledge transfer

\begin{tabular}{|c|c|c|c|}
\hline $\begin{array}{l}\text { Motivational } \\
\text { factors }\end{array}$ & Knowledge source & Knowledge recipient & Source \\
\hline Extrinsic & $\begin{array}{l}\text { - Rewards and appraisals } \\
\text { - Ideal salaries } \\
\text { - Satisfaction of work positions } \\
\text { - Stability of labor } \\
\text { - Promotions } \\
\text { - Reputation feedback }\end{array}$ & $\begin{array}{l}\text { - Rewards and appraisals } \\
\text { - Ideal salaries } \\
\text { - Satisfaction of work positions } \\
\text { - Stability of labor } \\
\text { - Promotions }\end{array}$ & $\begin{array}{l}\text { Ko et al. (2005; } \\
\text { Martín Cruz et al., } \\
\text { 2009; Hung et al., 2011; Yan and } \\
\text { Davison, 2013; Caligiuri, 2014; } \\
\text { Alhalhouli et al., 2014; Feet and Næss, } \\
\text { 2015; Wang and Hou, 2015). }\end{array}$ \\
\hline Intrinsic & $\begin{array}{l}\text { - Arduous relationship } \\
\text { - Altruism } \\
\text { - Shared Understanding } \\
\text { - Champions } \\
\text { - Train on enjoyment of help others }\end{array}$ & $\begin{array}{l}\text { - Arduous relationship } \\
\text { - Altruism } \\
\text { - Knowledge Trust } \\
\text { - Evaluate the quality of transferred knowledge } \\
\text { - Interest in shared knowledge } \\
\text { - Absorptive capacity } \\
\text { - Clearness and simple of decoding }\end{array}$ & $\begin{array}{l}\text { Ko et al. (2005; } \\
\text { Martín Cruz et al., 2009; } \\
\text { Hung et al., 2011; Yan and Davison, 2013; } \\
\text { Caligiuri, 2014; Alhalhouli et al., 2014; } \\
\text { Wang and Hou, 2015; Baporikar, 2017). }\end{array}$ \\
\hline
\end{tabular}


From the above Table 1, it can be noticed that the motivation factors of knowledge transfer behavior can be categorized as the following classes:

(i) Extrinsic motivational factors for knowledge source such as the rewards, promotions, satisfaction of work positions, stability of labour and reputation feedback

(ii) Extrinsic motivational factors for knowledge recipients such as rewards, appraisals, satisfaction of work positions and stability of labor

(iii) Intrinsic motivational factors for knowledge source such as arduous relationship, altruism, shared understanding, champions and train on enjoyment of help others

(iv) Intrinsic motivational factors for knowledge recipients such as arduous relationship, altruism, knowledge trust, absorptive capacity and evaluate the quality of transferred knowledge

\section{Research Methodology}

The basic strategy to achieve the research objectives is through using questionnaire to collect data from doctors and nurses in three Jordanian hospitals. The study questionnaire is designed as seven parts of 83 items and the questionnaire parts are: Demographic data (7 items); knowledge transfer (5 items); behavior of knowledge transfer (8 items); motivational extrinsic factors of knowledge source (13 items); motivational intrinsic factors of knowledge source (17 items); motivational extrinsic factors of knowledge recipients (10 items); motivational intrinsic factors of knowledge recipients (23 items). The questionnaire was designed based on many sources such as Lin (2007), Minbaeva et al. (2003) and Szulanski (1996).

The questionnaire validity was assured through two processes; (1) the initiated questionnaire was reviewed by three experts in the knowledge management domain and the given comments are updated in order to finalize the last questionnaire draft and (2) a pilot study was conducted with 51 health staff to assure the reliability and validity of the questionnaire. The validation processes confirm the effectiveness of the questionnaire parts and items to address the main aim of this study.

For effective data collection, there are many procedures are conducted; (1) the questionnaire was translated to Arabic language (the mother language of the students), (2) the questionnaire was distrusted using paper forms, (3) the research idea is explained very well to the respondents, (5) the questioner items are explained carefully and (6) the respondents take sufficient time to complete the questionnaire.

The data of this study is collected in the duration Jul 2018-Dec 2018 from 475 health staff in Jordanian hospitals namely; Albashir Hospital, Jordan University Hospital and
Al-Issra Hospital. The selection of these hospitals is due to providing of private and public health services.

The total population of the case study is 4690 health staff and according to Pallant (2016) the minimum required sample rate based on this population is $10 \%$. the data were collected from 475 health staff in the study area. The respondent answers collected based on 5-likert scale; "1 for strongly disagree (SD), 2 for Disagree (D), 3 for Neutral (N), 4 for Agree (A) and 5 for Strongly Agree (SA)". 5-likert scale is more focused than lower scales and produce relative responses means more than high scales (Dawes, 2008).

The study utilizes a non-probability sampling method namely quota and convenience sampling. The justification behind using the quota and convenience sampling method is due to the confidentiality policies in the hospitals sector. This confidentiality prevented the researcher from acquiring the data directly from the doctors and nurses in the hospitals, which prevent the selection of the individuals according to their characteristics such as positions and working roles (Albdour and Altarawneh, 2014). Regarding to quota technique, the judgment of sample selection depends on the usefulness of segment the proposed sample based on a specified proportion. In this research, the sample collected based on two strategies according to quota technique. Firstly, the data collection from various departments in the hospitals to ensures the usefulness of the collected data. Secondly, the data are collected based on the quota samples of each hospital. These two strategies are assured through the good supporting by the hospital's management offices.

The data analysis is conducted using SPSS 22.0 tool due to effectiveness of this tool in analyze the large quantitative sample. Many tests are conducted using SPSS such as validity, reliability, frequency and descriptive analysis.

\section{Discussion of the Findings}

This study has distributed a total of 938 questionnaires to the staff in three hospitals based on the quota of each hospital. A total of 589 responses were collected. Before proceeding for data analysis, the data must be examined for missing value, outliers and normality of distribution as well as the multicollinearity.

Researchers suggested that missing value must be checked before proceeding to other analyses (Hair et al., 2017). According to Hair et al. (2017), a questionnaire that misses more than $15 \%$ of the answers should be deleted. Missing value was checked in this study using the frequency analysis. Questionnaire that misses more than $15 \%$ of the responses is deleted. After examining the data, a total of 67 questionnaires were missing more than $15 \%$ of the answers. These responses were removed. In addition, a total of 21 responses were missing less than $15 \%$ of the answers. Missing answers 
were replaced by the mean score value. This makes the complete answers 522 responses.

on the other hand, Hair et al. (2017) indicated that outliers can be checked using the boxplot of the indicators of the variables (mean score value). The analysis of outliers was conducted by checking the boxplot of the mean score of the variables. Based on the analysis, 47 responses were considered as outliers due to the fact that their answers far from the mean score value and identified by the boxplot as outliers. The 47 responses were removed. This resulted in a total of 475 complete and usable responses.

Furthermore, Normality of the data can be checked by examining the skewness and kurtosis of the variables (Hair et al., 2017). Data is considered as normally distributed if the value of skewness and kurtosis are within the range of -2 to +2 . In other words, less than absolute 2 (Pallant, 2016). All the values of skewness as well as kurtosis are less than absolute 2 indicating that the data are normally distributed.

In addition, Multicollinearity occurs when the correlation between variables is high $(0.90)$ so that the independent variables predict each other rather than predicting the dependent variable (Hair et al., 2017). Pallant (2016) indicated that variables will not have multicollinearity issues if the value of tolerance larger than 0.10 and the value of Variance Inflation Factors (VIF) is less than 10. the values of tolerance for all the variables is larger than 0.10 and the value of VIF for all variables are less than 10. This leads to a conclusion that none of the variable have high correlation with another variables and there is no multicollinearity issues among the variables.

In conclusion the number of reliable and valid collected questionnaire is 475 and these responses can be used in the next data analysis

\section{Analysis of Demographic Data}

In this section, the background information of the respondents is presented. The purpose of this is to let the reader (s) known from whom this data was collected. Table 2 presents the gender, age, job title, experience, number of health tasks conducted by the respondents per day, level of collaboration between health staff to accomplish tasks and the need to collect new knowledge to serve health tasks.

In Table 2, the gender of the respondents of this study is presented. It shows that 321 or $67.6 \%$ are males while 154 or $32.4 \%$ are females. The sample of this study is dominated by the males. This could be due to the fact that majority of employees in Jordan are males while females considered less among the workforce of the country. On the other hand, the age of the respondents indicates that the highest percentage of the respondents $38.3 \%$ (182) is in the age range between 25 and 34 years. The second highest percentage is $25.9 \%$ (123) of the respondents are in the age group between 45 and 55 years. This is followed by 24\% (114) of the respondents in the age group between 35 and 44 years. Those less than 25 years accounted for $9.3 \%$ (44) and those more than 55 years are minority of $2.5 \%$ (12). A total of $71.6 \%$ of the respondents are younger than 45 years indicating that the majority are still in their middle career.

Furthermore, Job title refers to the profession that the respondents are doing. In this study, 269 or $56.6 \%$ of the respondents are medical doctors followed by $30.5 \%$ or 145 are nurses, $8 \%$ or 38 of the respondents stated that they are assistance of nurse. Others that include laboratories accounted to $4.8 \%$ or 23 of the respondents. Moreover, the experience of the respondents result indicates that highest percentage of $48.8 \%$ or 232 of the respondents have more than 10 years' experience. A total of 111 or $23.4 \%$ of the respondents have experience between 4 to 6 years, followed by 100 or $21.1 \%$ with experience between 7 to 9 years. Respondents with 1-3 years of experience accounted to $6.7 \%$ or 32 .

In addition, the number of health tasks conducted by the respondents per day showed that 122 or $25.7 \%$ of the respondents conducted between 11-20 tasks every day. This is followed by 83 of the respondents (17.5\%) conduct 31-40 tasks daily. A total of 79 or 16.6 of the respondents conduct 41-50 tasks in daily basis. 74 of the respondents $(15.6 \%)$ conduct more than 50 tasks a day. A total of 21 to 30 tasks are conducted by 73 or $15.4 \%$ of the respondents. 44 or $9.3 \%$ of the respondents conduct less than 11 tasks a day.

Also, the staffs highly collaborate between each other to accomplish the health tasks. The result in Table 2 shows that 367 or $77.3 \%$ of the respondents indicated that they are highly collaborative with each other. Medium level collaboration accounted to 67 or $14.1 \%$ between the respondents. low level collaboration was found among 41 or $8.6 \%$ of the respondents. Lastly, the respondents were asked to what extent they need to collect new knowledge to serve health cases. The result in Table 2 shows that 299 or $62.9 \%$ of the respondents frequently collect new knowledge. A total of 109 or $22.9 \%$ occasionally collect new knowledge. Rarely knowledge collection is conducted by 67 or $14.1 \%$ of the respondents.

In conclusion, the demographic analysis shows the respondents characteristics are useful to provide effective responses, which strength the findings of this study. The next section presents the descriptive analysis of the questionnaire data.

\section{Descriptive Analysis}

In this section, the descriptive information of the variables are given. Items of the variables as well as the dimension of each constructs and the overall mean score value of the constructs is given. The remark is based on the value given in Table 3 which shows the interpretation of the obtained mean score values. 
Table 2: Background information of respondents

\begin{tabular}{|c|c|c|c|}
\hline Variable & Label & Frequency & Percent \\
\hline \multirow[t]{2}{*}{ Gender } & Male & 321 & 67.6 \\
\hline & Female & 154 & 32.4 \\
\hline \multirow[t]{5}{*}{ Age } & Less than 25 years & 44 & 9.3 \\
\hline & $25-34$ years & 182 & 38.3 \\
\hline & $35-44$ years & 114 & 24.0 \\
\hline & $45-55$ years & 123 & 25.9 \\
\hline & More than 55 years & 12 & 2.5 \\
\hline \multirow[t]{4}{*}{ Job title } & Doctor & 269 & 56.6 \\
\hline & Nurse & 145 & 30.5 \\
\hline & Assistance Nurse & 38 & 8.0 \\
\hline & Others & 23 & 4.8 \\
\hline \multirow[t]{4}{*}{ Experience } & $1-3$ years & 32 & 6.7 \\
\hline & 4-6 years & 111 & 23.4 \\
\hline & $7-9$ years & 100 & 21.1 \\
\hline & More than 10 years & 232 & 48.8 \\
\hline \multirow[t]{6}{*}{ Number of health tasks } & Less than 11 tasks & 44 & 9.3 \\
\hline & $11-20$ tasks & 122 & 25.7 \\
\hline & 21-30 tasks & 73 & 15.4 \\
\hline & $31-40$ tasks & 83 & 17.5 \\
\hline & $41-50$ tasks & 79 & 16.6 \\
\hline & More than 50 tasks & 74 & 15.6 \\
\hline \multirow[t]{3}{*}{ Collaboration } & High & 367 & 77.3 \\
\hline & Medium & 67 & 14.1 \\
\hline & Low & 41 & 8.6 \\
\hline \multirow[t]{3}{*}{ Frequency of New knowledge collection } & Frequently & 299 & 62.9 \\
\hline & Occasionally & 109 & 22.9 \\
\hline & Rarely & 67 & 14.1 \\
\hline
\end{tabular}

$\mathrm{N}: 475$

Table 3: Questionnaire Criterion (Qawasmeh et al., 2013)

\begin{tabular}{lll}
\hline Scale index & Answer & Answers level \\
\hline $1-1.49$ & Strongly disagree & Very low \\
$1.5-2.49$ & Disagree & Low \\
$2.5-3.49$ & Neutral & Moderate \\
$3.5-4.49$ & Agree & High \\
$4.5-5$ & Strongly agree & Very high \\
\hline
\end{tabular}

Table 4: Level of knowledge transfer in hospital

\begin{tabular}{lllll}
\hline Construct & Variable & Items & Mean & Remark \\
\hline Knowledge Transfer in Hospital & Knowledge transfer (KT) & KT1 & 3.05 & Moderate \\
& & KT2 & 3.02 & Moderate \\
& & KT3 & 3.02 & Moderate \\
& & KT4 & 3.02 & Moderate \\
& Mean score value of KT & & 3.03 & Moderate \\
& Behavior of knowledge Transfer (BKT) & BKT1 & 3.36 & Moderate \\
& & BKT2 & 3.11 & Moderate \\
& & BKT3 & 3.05 & Moderate \\
& & BKT4 & 3.05 & Moderate \\
& & BKT5 & 3.07 & Moderate \\
Overall mean score value & BKT6 & 3.39 & 3.12 & Moderate \\
& & & 3.07 & Moderate \\
& & & & Moderate \\
\hline
\end{tabular}

Table 4 shows the mean score value of the knowledge transfer and behavior of knowledge transfer. It shows also the overall mean score value of the knowledge transfer in hospital. The table shows that for all the items of knowledge transfer the level is moderate. The mean score of the variables also showed a moderate level of agreement with the items. This indicates that the knowledge transfer is moderate level. 
For the behavior of knowledge transfer, it shows also that the level of the items is moderate as well as the level of the variable. Overall, the level of knowledge transfer in the hospital is moderate with 3.07.

The level of motivational extrinsic factors of knowledge source is given in Table 5. It shows that almost all the statement has a moderate level of agreement. The mean score value of RAS is 3.50 indicating high level of agreement while for the mean score ISS $($ mean $=2.95)$, PS $($ Mean $=3.20)$, WPS $($ Mean $=3.28)$, SLS $($ Mean = 3.36) and RFS $($ Mean = 3.41) indicating that all the variables has moderate level of agreement. The overall mean score value of motivational extrinsic factors of knowledge source is 3.28 indicating that there is moderate level among the respondents regarding the extrinsic factors.

The level of motivational intrinsic factors of knowledge source is given in Table 6. It shows that the level of almost all the items and variables is moderate. The level for ARS is 3.37 indicates a moderate agreement on the respondents for the statement pertaining to arduous relationship. Similarly, all the levels of other variables such as altruism, shared understanding, champions and enjoyment of helping others are in the moderate level. The overall mean of the motivational intrinsic factors of knowledge source is 3.19 indicating a moderate level of agreement on the intrinsic factors of knowledge source.

Table 5: Motivational extrinsic factors of knowledge source

\begin{tabular}{|c|c|c|c|c|}
\hline Construct & Variable & Items & Mean & Remark \\
\hline Motivational extrinsic factors & Reward and appraisals (RAS) & RAS1 & 3.51 & High \\
\hline \multirow[t]{18}{*}{ of knowledge source } & & RAS2 & 3.49 & Moderate \\
\hline & Mean of RAS & & 3.50 & High \\
\hline & Ideal Salaries (ISS) & ISS1 & 2.91 & Moderate \\
\hline & & ISS2 & 3.01 & Moderate \\
\hline & Mean of ISS & & 2.95 & Moderate \\
\hline & Promotions (PS) & PS1 & 3.17 & Moderate \\
\hline & & PS2 & 3.24 & Moderate \\
\hline & Mean of PS & & 3.20 & Moderate \\
\hline & Satisfaction of work position (WPS) & WPS1 & 3.38 & Moderate \\
\hline & & WPS2 & 3.18 & Moderate \\
\hline & Mean of WPS & & 3.28 & Moderate \\
\hline & Stability of Labor (SLS) & SLS1 & 3.38 & Moderate \\
\hline & & SLS2 & 3.34 & Moderate \\
\hline & Mean of SLS & & 3.36 & Moderate \\
\hline & Reputation Feedback (RFS) & RFS1 & 3.69 & High \\
\hline & & RFS2 & 3.25 & Moderate \\
\hline & & RFS3 & 3.30 & Moderate \\
\hline & Mean of RFS & & 3.41 & Moderate \\
\hline Overall mean & & & 3.28 & Moderate \\
\hline
\end{tabular}

Table 6: Level of motivational intrinsic factors of knowledge source

\begin{tabular}{|c|c|c|c|c|}
\hline Construct & Variable & Items & Mean & Remark \\
\hline Motivational intrinsic factors & Arduous relationship (ARS) & ARS1 & 3.39 & Moderate \\
\hline \multirow[t]{18}{*}{ of knowledge source } & & ARS2 & 3.35 & Moderate \\
\hline & Mean of ARS & & 3.37 & Moderate \\
\hline & Altruism (ALS) & ALS1 & 3.29 & Moderate \\
\hline & & ALS2 & 3.73 & High \\
\hline & & ALS3 & 3.27 & Moderate \\
\hline & Mean of ALS & & 3.43 & Moderate \\
\hline & Shared understanding (SUS) & SUS1 & 3.67 & High \\
\hline & & SUS2 & 3.12 & Moderate \\
\hline & & SUS3 & 3.22 & Moderate \\
\hline & Mean of SUS & & 3.41 & High \\
\hline & Champions (CHS) & CHS1 & 3.33 & Moderate \\
\hline & & CHS2 & 3.22 & Moderate \\
\hline & & CHS3 & 3.74 & High \\
\hline & Mean of CHS & & 3.43 & Moderate \\
\hline & Enjoyment to help others (EHS) & EHS1 & 3.17 & Moderate \\
\hline & & EHS2 & 3.15 & Moderate \\
\hline & & EHS3 & 3.25 & Moderate \\
\hline & Mean of EHS & & 3.19 & Moderate \\
\hline
\end{tabular}


Table 7: Level of motivational extrinsic factors of knowledge recipient

\begin{tabular}{|c|c|c|c|c|}
\hline Construct & Variable & Items & Mean & Remark \\
\hline Motivational Extrinsic Factors & Rewards and appraisal (RAR) & RAR1 & 3.23 & Moderate \\
\hline \multirow[t]{14}{*}{ of Knowledge Recipient } & & RAR2 & 3.22 & Moderate \\
\hline & Mean of RAR & & 3.22 & Moderate \\
\hline & Ideal Salaries (ISR) & ISR1 & 3.36 & Moderate \\
\hline & & ISR2 & 3.28 & Moderate \\
\hline & Mean of ISR & & 3.32 & Moderate \\
\hline & Promotions (PR) & PR1 & 3.16 & Moderate \\
\hline & & PR2 & 3.14 & Moderate \\
\hline & Mean of PR & & 3.15 & Moderate \\
\hline & Satisfaction of Work Positions (WPR) & WPR1 & 3.20 & Moderate \\
\hline & & WPR2 & 3.10 & Moderate \\
\hline & Mean of WPR & & 3.15 & Moderate \\
\hline & Stability of Labour (SLR) & SLR1 & 3.28 & Moderate \\
\hline & & SLR2 & 3.42 & Moderate \\
\hline & Mean of SLR & & 3.30 & Moderate \\
\hline Overall mean & & & 3.28 & Moderate \\
\hline
\end{tabular}

Table 8: Motivational extrinsic factors of knowledge recipient

\begin{tabular}{|c|c|c|c|c|}
\hline Construct & Variable & Items & Mean & Remark \\
\hline Motivational Extrinsic Factors & Arduous relationship (ARR) & ARR1 & 3.08 & Moderate \\
\hline \multirow[t]{28}{*}{ of Knowledge Recipient } & & ARR2 & 3.10 & Moderate \\
\hline & Mean of ARR & & 3.09 & Moderate \\
\hline & Altruism (ALR) & ALR1 & 3.36 & Moderate \\
\hline & & ALR2 & 3.37 & Moderate \\
\hline & & ALR3 & 3.43 & Moderate \\
\hline & Mean of ALR & & 3.39 & Moderate \\
\hline & Knowledge trust (KTR) & KTR1 & 3.27 & Moderate \\
\hline & & KTR2 & 3.32 & Moderate \\
\hline & & KTR3 & 3.73 & Moderate \\
\hline & Mean of KTR & & 3.44 & Moderate \\
\hline & Evaluate the quality of knowledge (QKR) & QKR1 & 3.13 & Moderate \\
\hline & & QKR2 & 3.12 & Moderate \\
\hline & & QKR3 & 3.65 & High \\
\hline & Mean of QKR & & 3.30 & Moderate \\
\hline & Knowledge Interest (KIR) & KIR1 & 3.24 & Moderate \\
\hline & & KIR2 & 3.34 & Moderate \\
\hline & & KIR3 & 3.20 & Moderate \\
\hline & Mean of KIR & & 3.26 & Moderate \\
\hline & Absorptive Capacity (ACR) & ACR1 & 3.49 & Moderate \\
\hline & & ACR2 & 3.46 & Moderate \\
\hline & & ACR3 & 2.99 & Moderate \\
\hline & Mean of ACR & & 3.40 & Moderate \\
\hline & Knowledge Clearance (KCR) & KCR1 & 3.36 & Moderate \\
\hline & & KCR2 & 3.26 & Moderate \\
\hline & & KCR3 & 3.33 & Moderate \\
\hline & & KCR4 & 3.25 & Moderate \\
\hline & Mean of KCR & & 3.30 & Moderate \\
\hline & Overall mean & & 3.31 & Moderate \\
\hline
\end{tabular}

The level of motivational extrinsic factors of knowledge recipient is given in Table 7. The table shows that the level of all variables is less than 3.49 and greater than 2.5 indicating that the level is moderate and respondents moderately agree on the statement of the variables. The overall mean score value of the motivational extrinsic factors of knowledge recipient is 3.28 indicating a moderate agreement level on the items and the variables.
The level of motivational extrinsic factors of knowledge recipient is given in Table 8 . It can be seen from Table 8 that all the items have moderate level of agreement with almost all the items has also moderate level. The overall mean of the motivational extrinsic factors of knowledge recipient is 3.31 indicates that the level is moderate.

Based on the above findings, it can be concluded that the heath staffs are aware of the importance of 
knowledge transfer in the hospitals and they believe that the behavior of knowledge transfer could be enhanced using extrinsic and intrinsic motivational factors.

For knowledge sources, there are many extrinsic motivational factors can be applied; reward and appraisals, ideal salaries, promotions, satisfaction of work position, stability of labor and reputation feedback. On the other hand, there are many intrinsic factors would motivate the knowledge transfer by the knowledge source; arduous relationship, altruism, shared understanding, champions and enjoyment to help others.

For knowledge recipients, the extrinsic motivational factors that can be adopted are: Reward and appraisals, ideal salaries, promotions, satisfaction of work position and stability of labor. On the other hand, there are many intrinsic factors would motivate the knowledge transfer by the knowledge recipients; arduous relationship, altruism, shared understanding, champions and enjoyment to help others.

\section{Conclusion and Future Works}

This study investigates the motivational factors that could be applied to enhance the knowledge transfer among the health staff in the hospitals. The data were collected using questionnaire from 475 doctors and nurses that works in three Jordanian hospitals. The analysis of the collected data shows that there are many extrinsic motivational factors would be adopted to improve the knowledge transfer by the knowledge source and recipients such as reward, ideal salaries, promotions, satisfaction of work position, stability of labor and reputation feedback. On the other hand there are many intrinsic motivational factors that would be applied to enhance the knowledge transfer such as arduous relationship, altruism, shared understanding, champions and enjoyment to help others.

In the future, the structured equation model will be conducted on the study data in order to analyze the relationship between the various variables in this study. Also, the variable of ideal knowledge transfer is important to be included in the future works. The ideal knowledge transfer focuses on provide the motivational factors based on the quality and quantity of the transfer knowledge among the health staff.

\section{Acknowledgment}

The authors would like to thank the management and staff of Albashir Hospital, Jordan University Hospital and Al-Issra Hospital for the help in collecting the data.

\section{Author's Contributions}

Ahmad Aabed Al-Hayy Al-Dalaien: Conducted the literature review and contributed in the data collection.
Sulfeeza Mohd Drus: Contributed in the research methodology and refining the questionnaire of data collection.

Hairoladenan Kasim and Ali Taha Al-Oqaily: Contributed by analyzing the data and presenting the findings of this study. All the authors contributed to the discussion, conclusion and proofreading and editing the paper.

\section{Ethics}

This article is original and contains unpublished material. The corresponding author confirms that all of the other authors have read and approved the manuscript and no ethical issues involved.

\section{References}

Adams, J.S., 1963. Towards an understanding of inequity. J. Abnormal Soc. Psychol., 67: 422-436. DOI: $10.1037 / \mathrm{h} 0040968$

Ahmad, N.A., S.M. Drus, N.A.A. Bakar and M.M. Othman, 2018. A systematic review of enterprise architecture adoption models. Int. J. Eng. Technol., 7: 369-374. DOI: 10.14419/ijet.v7i4.35.22763

Al-Dala'Ien, A.A.A., M.A. Mahmoud and M.S. Ahmad, 2016. A model for measuring articles knowledgeability levels. J. Theoretical Applied Inform. Technol., 88: 1-10.

Al-Dala'Ien, A.A.A., M.A. Mahmoud and M.S. Ahmad, 2015. An investigation on measuring accuracy of explicit knowledge sources in universities. J. Inform. Knowledge Manage., 5: 36-44.

Al-Oqaily, A.L.I., Z.B. Hassan, A.A.H. Al-Dala'ien and A.M. Rashid, 2015. Develop practical methods of knowledge measurement in universities. J. Theoretical Applied Inform. Technol., 73: 301-306.

Albdour, A.A. and I.I. Altarawneh, 2014. Employee engagement and organizational commitment: Evidence from Jordan. Int. J. Bus., 19: 192-212.

Alaaraj, S., Z.A. Mohamed and U.S. Ahmad Bustamam, 2018. External growth strategies and organizational performance in emerging markets: The mediating role of inter-organizational trust. Rev. Int. Bus. Strategy, 28: 206-222. DOI: 10.1108/RIBS-09-2017-0079

Alaarj, S., Z. Abidin-Mohamed and U.S.B.A. Bustamam, 2016. Mediating role of trust on the effects of knowledge management capabilities on organizational performance. Proc. Soc. Behav. Sci., 235: 729-738. DOI: 10.1016/j.sbspro.2016.11.074

Alaarj, S., Z.A. Mohamed and U.S. Bustamam, 2017a. Do knowledge management capabilities reduce the negative effect of environment uncertainties on organizational performance? A study of public listed companies in Malaysia. Int. J. Econ. Res., 14: 443-456. 
Alaarj, S., Z.A. Mohamed and U.S. Bustamam, 2017b. The effect of knowledge management capabilities on performance of companies: A study of service sector. Int. J. Econ. Res., 14: 457-470.

Alaarj, S., Z.A. Mohamed and U.S.B.A. Bustamam, 2015. The effect of knowledge management capabilities on the performance of Malaysian largescale organizations: An empirical study. Adv. Global Bus. Res., 12: 1024-1038.

Alhalhouli, Z.T., Z. Hassan and C.S. Der, 2014. Factors affecting knowledge sharing behavior among stakeholders in Jordanian hospitals using social networks. Int. J. Comput. Inform. Technol., 3: 919-928.

Alksasbeh, M.Z., A.A.H. Al-Dala and B.A. Alqaraleh, 2018. Factors that influence the success of knowledge management implementation in Jordanian higher education institutions. Res. J. Applied Sci. Eng. Technol., 15: 249-260. DOI: 10.19026/rjaset.15.5907

Argote, L. and E. Fahrenkopf, 2016. Knowledge transfer in organizations: The roles of members, tasks, tools and networks. Organiz. Behav. Human Dec. Processes, 136: 146-159. DOI: 10.1016/j.obhdp.2016.08.003

Baporikar, N., 2017. Innovation Implementation: The Critical Facets. In: Driving Innovation and Business Success in the Digital Economy, Oncioiu, I. (Ed.), IGI Global, Hershey, ISBN-10: 1522517804, pp: 41-54.

Bustinza, O.F., E. Gomes, F. Vendrell-Herrero and T. Baines, 2019. Product-service innovation and performance: The role of collaborative partnerships and R\&D intensity. R\&D Manage., 49: 33-45.

DOI: $10.1111 / \mathrm{radm} .12269$

Caligiuri, P., 2014. Many moving parts: Factors influencing the effectiveness of HRM practices designed to improve knowledge transfer within MNCs. J. Int. Bus. Stud., 45: 63-72. DOI: 10.1057/jibs.2013.52

Cuervo-Cazurra, A., M.J. Nieto and A. Rodríguez, 2018. The impact of R\&D sources on new product development: Sources of funds and the diversity versus control of knowledge debate. Long Range Plann., 51: 649-665. DOI: 10.1016/j.lrp.2017.06.004

Dammaj, A., A. Alawneh, A.A. Hammad and R.J. Sweis, 2016. Investigating the relationship between knowledge sharing and service quality in private hospitals in Jordan. Int. J. Product. Quality Manage., 17: 437-455. DOI: 10.1504/IJPQM.2016.075248

Dawes, J.G., 2008. Do data characteristics change according to the number of scale points used? An experiment using 5 point, 7 point and 10 point scales. Int. J. Market Res., 50: 61-104.

DOI: $10.1177 / 147078530805000106$

Diep, N.A., C. Cocquyt, C. Zhu and T. Vanwing, 2016. Predicting adult learners' online participation: Effects of altruism, performance expectancy and social capital. Comput. Educ., 101: 84-101.

DOI: 10.1016/j.compedu.2016.06.002
Drus, S.M., S.S.M. Shariff and M. Othman, 2017. Knowledge audit framework: A case study of the Malaysian electricity supply industry. J. Inform. Commun. Technol., 16: 103-120.

Feet, V. and A.F. Næss, 2015. A qualitative study of improvement and knowledge transfer in Norwegian public hospitals. Master's Thesis, NTNU.

Goodall, A.H. and A. Bäker, 2015. A Theory Exploring how Expert Leaders Influence Performance in Knowledge-Intensive Organizations. In: Incentives and Performance, Springer, Cham, pp: 49-67.

Grossi, G., K.M. Kallio, M. Sargiacomo and M. Skoog, 2019. Accounting, performance management systems and accountability changes in knowledgeintensive public organizations: A literature review and research agenda. Account. Audit. Accountability J. DOI: 10.1108/AAAJ-02-2019-3869

Hanaysha, J.R. and M. Majid, 2018. Employee motivation and its role in improving the productivity and organizational commitment at higher education institutions. J. Entrepreneurship Bus. DOI: $10.17687 /$ JEB.0601.02

Hair Jr, J.F., M. Sarstedt, C.M. Ringle and S.P. Gudergan, 2017. Advanced Issues in Partial Least Squares Structural Equation Modeling. 1st Edn., Sage Publications, ISBN-10: 1483377393, pp: 272.

Hislop, D., R. Bosua and R. Helms, 2018. Knowledge management in organizations: A critical introduction. Oxford University Press.

Hung, S.Y., A. Durcikova, H.M. Lai and W.M. Lin, 2011. The influence of intrinsic and extrinsic motivation on individuals' knowledge sharing behavior. Int. J. Human-Comput. Stud., 69: 415-427. DOI: 10.1016/j.ijhcs.2011.02.004

Jasimuddin, S.M., J. Li and N. Perdikis, 2017. The relationships of knowledge recipients and knowledge transfer at Japanese MNCs based in China. Soc. Intell. Leadership Problem Solv., 16: 181-194. DOI: 10.4324/9781315129525-10

Kasim, H.A. and S.M. Drus, 2018. Formulating a digital energy hub framework to inculcate knowledge sharing practices for energy sectors. Adv. Sci. Lett., 24: 1758-1762. DOI: 10.1166/asl.2018.11153

Kim, Y.M., D. Newby-Bennett and H.J. Song, 2012. Knowledge sharing and institutionalism in the healthcare industry. J. Knowledge Manage., 16: 480-494. DOI: 10.1108/13673271211238788

Ko, D.G., L.J. Kirsch and W.R. King, 2005. Antecedents of knowledge transfer from consultants to clients in enterprise system implementations. MIS Quarterly, 29: 59-85. DOI: $10.2307 / 25148668$

Kumar, J. and L.S. Ganesh, 2009. Research on knowledge transfer in organizations: A morphology. J. Knowl. Manage., 13: 161-174.

Lin, H.F., 2007. Effects of extrinsic and intrinsic motivation on employee knowledge sharing intentions. J. Inform. Sci., 33: 135-149. 
Loebbecke, C., P.C. van Fenema and P. Powell, 2016. Managing inter-organizational knowledge sharing. J. Strategic Inform. Syst., 25: 4-14. DOI: $10.1016 /$ j.jsis.2015.12.002

Lombardi, S., V. Cavaliere, L. Giustiniano and F. Cipollini, 2019. What money cannot buy: The detrimental effect of rewards on knowledge sharing. Eur. Manage. Rev. DOI: 10.1111/emre.12346

Martín Cruz, N., V. Martín Pérez and C. Trevilla Cantero, 2009. The influence of employee motivation on knowledge transfer. J. Knowledge Manage., 13: 478-490. DOI: 10.1108/13673270910997132

Minbaeva, D., T. Pedersen, I. Björkman, C.F. Fey and H.J. Park, 2003. MNC knowledge transfer, subsidiary absorptive capacity and HRM. J. Int. Bus. Stud., 34: 586-599. DOI: 10.1057/palgrave.jibs.8400056

Nonaka, I. and R. Toyama, 2015. The KnowledgeCreating theory Revisited: Knowledge Creation as a Synthesizing Process. In: The Essentials of Knowledge Management, Palgrave Macmillan, London, pp: 95-110.

Osterloh, M. and B.S. Frey, 2000. Motivation, knowledge transfer and organizational forms. Organiz. Sci., 11: 538-550.

Pallant, J., 2016. SPSS Survival Manual. 1st Edn., McGraw-Hill, Maidenhead, ISBN-10: 033526154X, pp: 352 .

Paulin, D. and K. Suneson, 2015. Knowledge transfer, knowledge sharing and knowledge barriers-three blurry terms in KM. Lead. Issues Knowledge Manage., 2: 73-73.

Prestmo, A., G. Hagen, O. Sletvold, J.L. Helbostad and P. Thingstad, et al., 2015. Comprehensive geriatric care for patients with hip fractures: A prospective, randomised, controlled trial. Lancet, 385: 1623-1633. DOI: 10.1016/S0140-6736(14)62409-0

Qawasmeh, F.M., N. Darqal and I.F. Qawasmeh, 2013. The role of organization culture in achieving organizational excellence: Jadara University as a case study. Management, 2: 05-19.

Radaelli, G., E. Lettieri, M. Mura and N. Spiller, 2014. Knowledge sharing and innovative work behaviour in healthcare: A micro-level investigation of direct and indirect effects. Creativity Innovat. Manage., 23: 400-414. DOI: 10.1111/caim.12084

Raziq, A. and R. Maulabakhsh, 2015. Impact of working environment on job satisfaction. Proc. Econom. Finance, 23: 717-725.

DOI: $10.1016 / \mathrm{S} 2212-5671(15) 00524-9$

Razmerita, L., K. Kirchner and P. Nielsen, 2016. What factors influence knowledge sharing in organizations? A social dilemma perspective of social media communication. J. Knowledge Manage., 20: 1225-1246. DOI: 10.1108/JKM-03-2016-0112.

Serenko, A. and N. Bontis, 2016. Negotiate, reciprocate, or cooperate? The impact of exchange modes on interemployee knowledge sharing. J. Knowledge Manage., 20: 687-712. DOI: 10.1108/JKM-10-2015-0394.
Serrat, O., 2017. Building a Learning Organization. In: Knowledge Solutions, Springer, Singapore, pp: 57-67.

Sheng, M.L., S.Y. Chang, T. Teo and Y.F. Lin, 2013. Knowledge barriers, knowledge transfer and innovation competitive advantage in healthcare settings. Manage. Dec., 51: 461-478.

DOI: 10.1108/00251741311309607

Suliman, M., S. Aloush, M. Aljezawi and M. AlBashtawy, 2018. Knowledge and practices of isolation precautions among nurses in Jordan. Am. J. Infect. Control, 46: 680-684. DOI: 10.1016/j.ajic.2017.09.023

Svärd, V., 2017. Assessing children at risk: Organizational and professional conditions within children's hospitals. Child Family Soc. Work, 22: 81-91. DOI: $10.1111 / \mathrm{cfs} .12291$

Szulanski, G., 1996. Exploring internal stickiness: Impediments to the transfer of best practice within the firm. Strategic Manage. J., 17: 27-43.

DOI: $10.1002 / \mathrm{smj} .4250171105$

Tsai, M.T. and N.C. Cheng, 2012. Understanding knowledge sharing between it professionals-an integration of social cognitive and social exchange theory. Behav. Inform. Technol., 31: 1069-1080. DOI: $10.1080 / 0144929 X .2010 .550320$

Tsai, Y., 2014. Learning organizations, internal marketing and organizational commitment in hospitals. BMC Health Services Res., 14: 152-152. DOI: $10.1186 / 1472-6963-14-152$

Wang, W.T. and Y.P. Hou, 2015. Motivations of employees' knowledge sharing behaviors: A selfdetermination perspective. Inform. Organiz., 25: 1-26. DOI: 10.1016/j.infoandorg.2014.11.001

$\mathrm{Wu}, \mathrm{Y}$. and W. Zhu, 2012. An integrated theoretical model for determinants of knowledge sharing behaviours. Kybernetes, 41: 1462-1482. DOI: $10.1108 / 03684921211276675$

Yacoub, M.I., W.M. Demeh, M.W. Darawad, J.L. Barr and A.M. Saleh et al., 2014. An assessment of diabetes-related knowledge among registered nurses working in hospitals in Jordan. Int. Nurs. Rev., 61: 255-262. DOI: 10.1111/inr.12090

Yan, Y. and R.M. Davison, 2013. Exploring behavioral transfer from knowledge seeking to knowledge contributing: The mediating role of intrinsic motivation. J. Assoc. Inform. Sci. Technol.gy, 64: 1144-1157. DOI: 10.1002/asi.22820

Zhang, D., F. Zhang, M. Lin and H.S. Du, 2017. Knowledge sharing among innovative customers in a virtual innovation community: The roles of psychological capital, material reward and reciprocal relationship. Online Inform. Rev., 41: 691-709. DOI: 10.1108/OIR-08-2016-0226 